Proc. Indian Acad. Sci. (Earth Planet. Sci.), Vol. 95, No. 3, November 1986, pp. 409-416.

(C) Printed in India.

\title{
Seasonal and solar cycle variations of night-time anomalous enhance- ments in total electron content
}

\author{
N BALAN $\dagger$, P B RAO and K N IYER* \\ Department of Physics, University of Kerala, Trivandrum 695 581, India \\ * Department of Physics, Saurashtra University, Rajkot 360005 , India
}

MS received 25 June 1984; revised 28 May 1985

\begin{abstract}
Seasonal and solar cycle variations of the various characteristics of night-time anomalous enhancements in total electron content (TEC) of the ionosphere are presented for a low latitude station, Hawaii by considering TEC data for a full solar cycle. All the characteristics of the TEC enhancements have seasonal and solar cycle dependence. TEC enhancement characteristics such as frequency of occurrence, amplitude and duration are positively correlated with solar activity. The possible source mechanisms for the observed enhancements are also discussed.
\end{abstract}

Keywords. Seasonal variations; solar cycle variations; anomalous enhancement; total electron content.

\section{Introduction}

It is well known that the electron density $N_{e}$ and total electron content (TEC) of the ionosphere do not decrease throughout the night as predicted by a simple theory. Anomalous enhancements in these parameters have often been observed under a wide range of geophysical conditions (eg: Evans 1965; Klobucher et al 1968; Young et al 1970; Janve et al 1979; Davies et al 1979; Essex and Klobuchar, 1980; Leitinger et al 1982). The characteristics of these enhancements have an important bearing on the source mechanisms responsible for the maintenance of night-time ionosphere (Titheridge 1968a).

Although detailed studies have been made on various aspects of the night-time TEC enhancements, one aspect that has not yet received any attention is the effect of solar cycle variation on the various characteristics of the phenomenon. Some mechanisms have been proposed which might be responsible for the observed TEC enhancements but none could be identified with any degree of certainty. In order to understand the importance of the various source mechanisms, it is essential to build a fairly comprehensive picture on all observational aspects of the phenomenon. In this paper, we present the seasonal and solar cycle variations of the various characteristics of the night-time TEC enhancements for a low latitude station, Hawaii, by considering TEC data for nearly a full solar cycle (September 1964-December 1973). The possible source mechanisms for the observed TEC enhancements are also discussed.

$\dagger$ to whom all corrospondence should be addressed 


\section{Experimental data and analysis}

The TEC data derived from Faraday rotation measurements of the VHF telemetry transmissions of Syncom-3 and ATS-1 geostationary satellites by Yuen and Roelofs (1971) and Roelofs (1973) at Hawaii $\left(21^{\circ} 15^{\prime} \mathrm{N}, 157^{\circ} 46^{\prime} \mathrm{W}\right)$ from September 1964 to December 1973 from the data base for the study. Syncom-3 data is used for the period September 1964-December 1966 and ATS-1 data for the remaining period. The subionospheric point of ATS- 1 corresponding to an altitude of $400 \mathrm{~km}$ is $\left(19 \cdot 7^{\circ} \mathrm{N}, 157 \cdot 2^{\circ} \mathrm{W}\right)$ and for Syncom-3 the corresponding coordinates are $\left(19 \cdot 7^{\circ} \mathrm{N}\right.$, $\left.159 \cdot 3^{\circ} \mathrm{W}\right)$ in 1964 and $\left(19 \cdot 1^{\circ} \mathrm{N}, 161.0^{\circ} \mathrm{W}\right)$ in 1966.

In characterizing a night-time TEC enhancement, the same criterion as adopted by Young et al (1970) is applied. Accordingly, an anomalous TEC enhancement is defined as the excess content. $\triangle T E C$ which remains after the exponentially decaying background part of the diurnal content is subtracted from the total content. For the present study, as done by Young et al (1970), only those enhancements which have an amplitude $\geqslant 20 \%$ of the background content have been considered. The majority of the enhancements are found to have a single peak either in pre-midnight or in post-midnight hours whereas a few have peaks in both halves of the night. In the case of enhancements having double peaks, only the prominent peak is considered for statistical study. The enhancements are divided into pre-midnight and post-midnight enhancements depending on the local time at which the prominent peak of the enhancements occurs. As the TEC enhancements at low latitudes are independent of geomagnetic activity (Tilteridge 1968b and

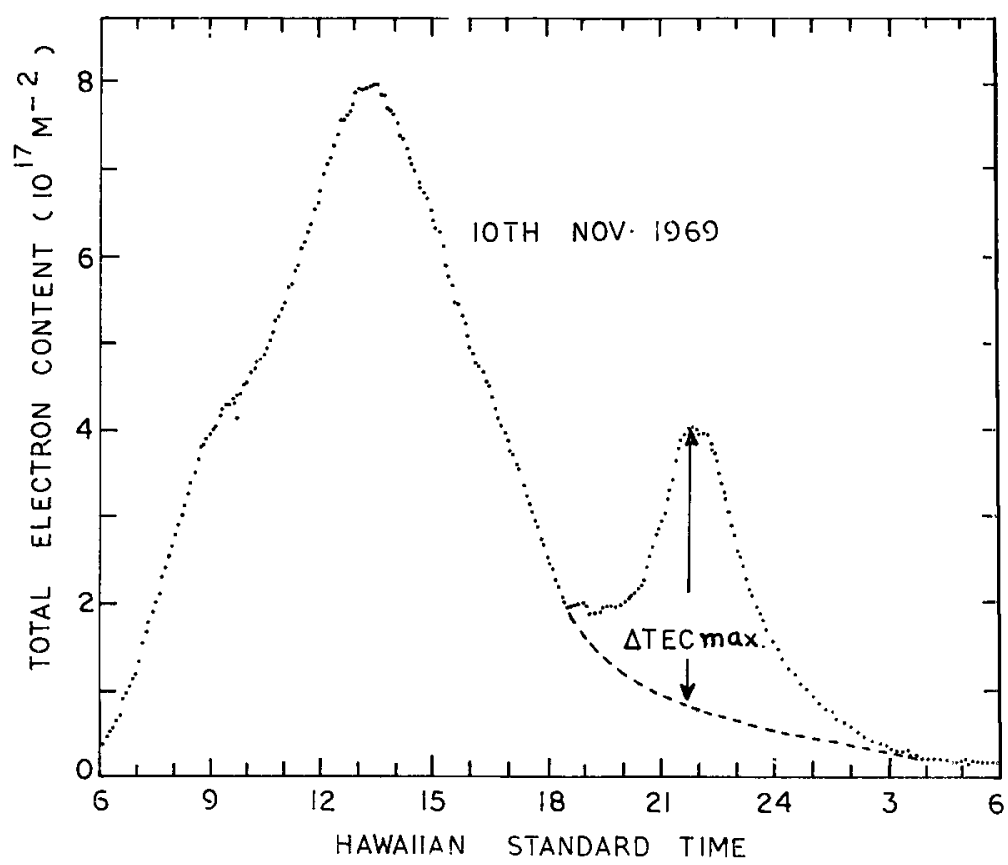

Figure 1. Diurnal variation of TEC at Hawaii on a solar maximum day illustrating the occurrence of a strong night-time TEC enhancement. 
Young et al 1970), no distinction is made between the quiet night and disturbed night enhancements. An example of the diurnal variation of TEC at Hawaii on a solar maximum day illustrating the occurrence of a strong night-time anomalous enhancement is shown in figure 1. As indicated in the figure, the amplitude of the TEC enhancement can be as much as three times the night-time background content.

\section{Results}

\subsection{Frequency and time of occurrence}

During the period under study, covering nearly a full solar cycle, a total of about 1670 night-time TEC enhancements have been observed at Hawaii. The histograms of the percentage of occurrence in each month for pre-midnight and post-midnight enhancements and the monthly mean Zurich relative sun spot numbers for the whole period of study are shown in figure 2 . It is seen that the night-time TEC

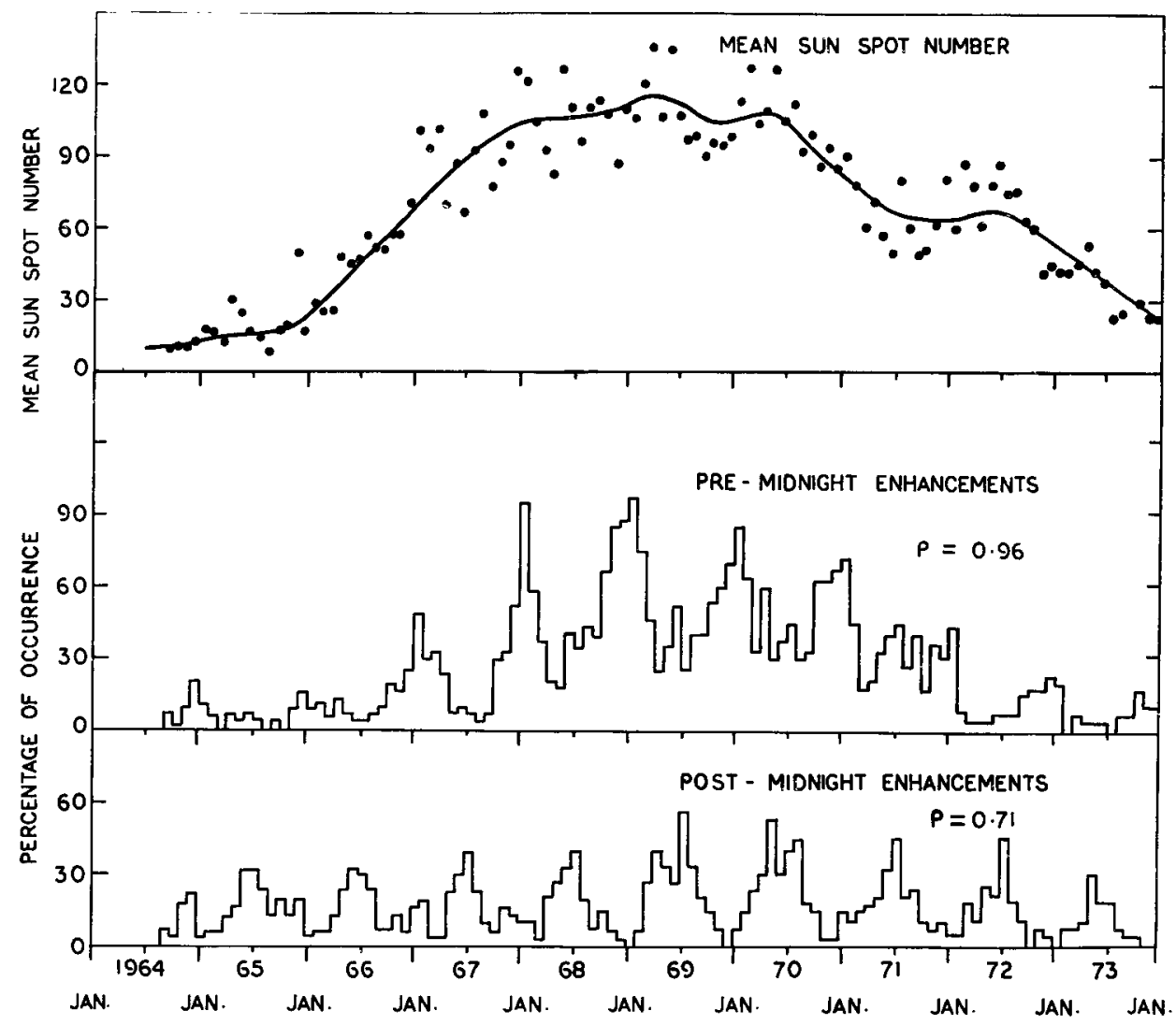

Figure 2. Dependence of the frequency of occurrence(\%) of pre-midnight and post-midnight TEC enhancements on solar activity during the period 1964-73 at Hawaii. Top portion of the figure gives the variation of monthly mean sun spot number. 


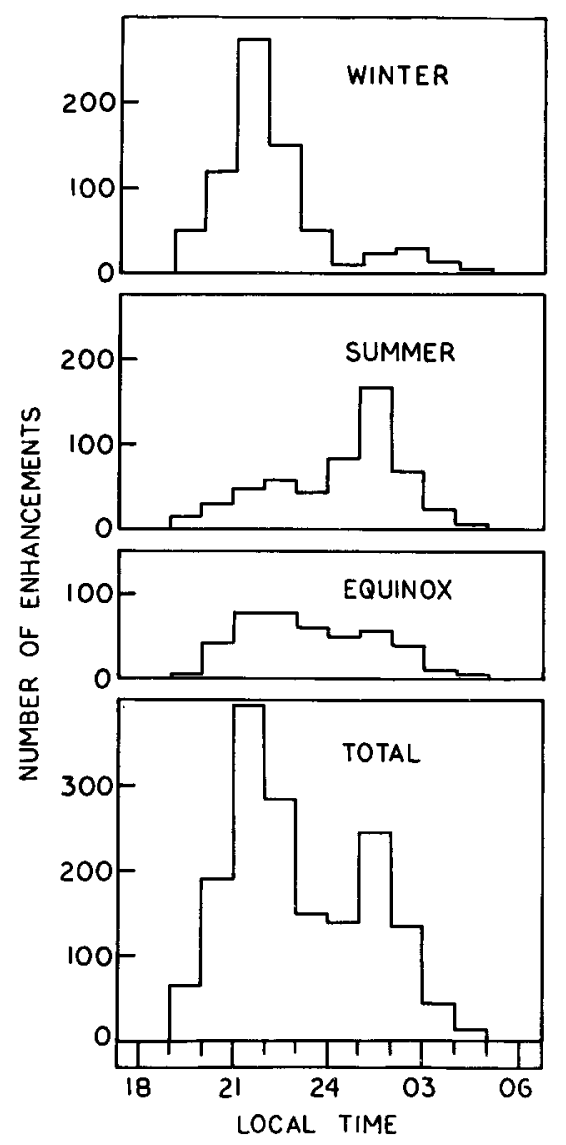

Figure 3. Distribution of the occurrence time of the peak of TEC enhancement at Hawaii for each season and for all the data combined.

enhancements occur in all seasons, more frequently in winter and less so in summer and equinox. Out of the total number of 1670 enhancements, 675 occur in winter, 570 in summer and 425 in equinox. Frequency of occurrence of pre-midnight and post-midnight enhancements, are well correlated with solar activity with correlation coefficients of 0.96 and 0.71 respectively. During the solar maximum year (1969), $77 \%$ of the nights have TEC enhancements of which $55 \%$ occur during pre-midnight hours and $22 \%$ during post-midnight hours. During the solar minimum year (1973), only $16 \%$ of the nights have TEC enhancements of which $7 \%$ occur during pre-midnight hours and $9 \%$ during post-midnight hours.

TEC enhancements can maximize anywhere from 1900 to 0500 LT. Figure 3 shows the distributions of the occurrence times of the enhancements peak in winter, summer, equinox and for all the data taken together. In winter, more than $80 \%$ of the enhancements maximize during pre-midnight hours and the most probable time of maximization is $2100-2200$ LT. In summer, more than $65 \%$ of the enhancements maximize during post-midnight hours, the most probable time being 0100-0200 LT. During equinox, there is no definite probable time for content maximization although the frequency of occurrence is slightly greater during the pre-midnight hours. The bottom portion of the figure shows the distribution of the 
times of occurrence of the enhancement peak for all the data taken together. In this plot, two peaks are seen naturally, one at 2100-2200 LT and the other at 0100-0200 LT, which correspond to the winter and summer enhancements respectively.

\subsection{Time duration and amplitude}

Histograms showing the distributions of the half-amplitude duration $(\tau)$ and the amplitude $\left(\triangle T E C_{\text {max }}\right.$ ) of pre-midnight and post-midnight TEC enhancements for all the data are shown in figures 4 (a) and (b) respectively. The most probable value of $\tau$ for pre-midnight and post-midnight enhancements are about the same with a value of about 100 minutes. However, a few cases of TEC enhancements lasting throughout night have been observed especially during summer. In figure 4(b), the number of enhancements varies sharply with the amplitude, $\triangle T E C_{\text {max }}$. Premidnight and post-midnight enhancements can have values of $\triangle T E C_{\text {max }}$ in the ranges $0.2 \times 10^{17}-3 \times 10^{17} \mathrm{~m}^{-2}$ and $0.1 \times 10^{17}-2 \times 10^{17} \mathrm{~m}^{-2}$ respectively. The most probable values for the two cases are $0.6 \times 10^{17} \mathrm{~m}^{-2}$ and $0.4 \times 10^{17} \mathrm{~m}^{-2}$. Normalized (with respect to the starting level of the enhancement) $\triangle \mathrm{TEC}_{\max }$ has been found to range from $15 \%$ to $220 \%$ and the most probable value is around $50 \%$. Enhancements which are greater that $100 \%$ are about $1 / 4$ of the total number.

Seasonal variations of $\tau$ of pre-midnight and post-midnight enhancements presented in figure 5 (dashed curves) averaged for all the years, show a broad

(a)

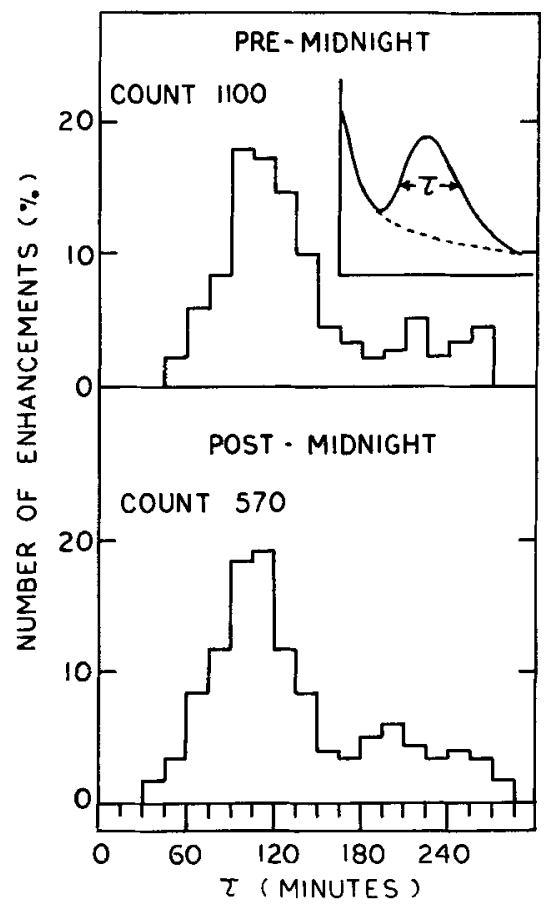

(b)

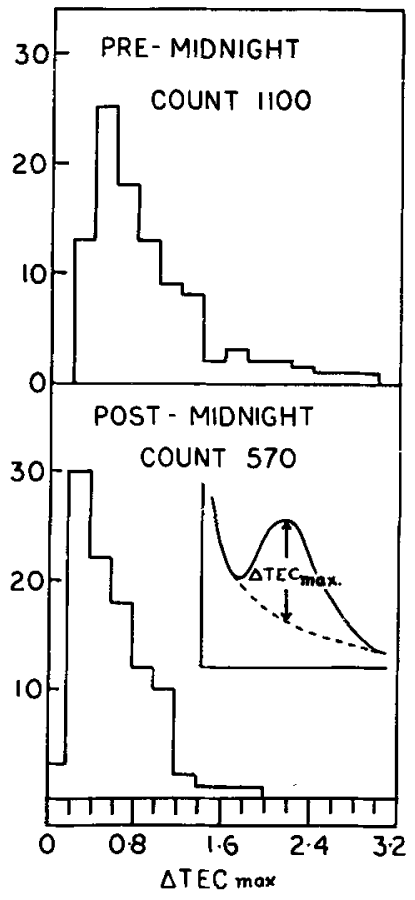

Figure 4. Distribution of (a) the half-amplitude duration ( $\tau$ ) and (b) the amplitude $\left(\triangle \mathrm{TEC}_{\max }\right)$ of pre-midnight and post-midnight TEC enhancements at Hawaii. 


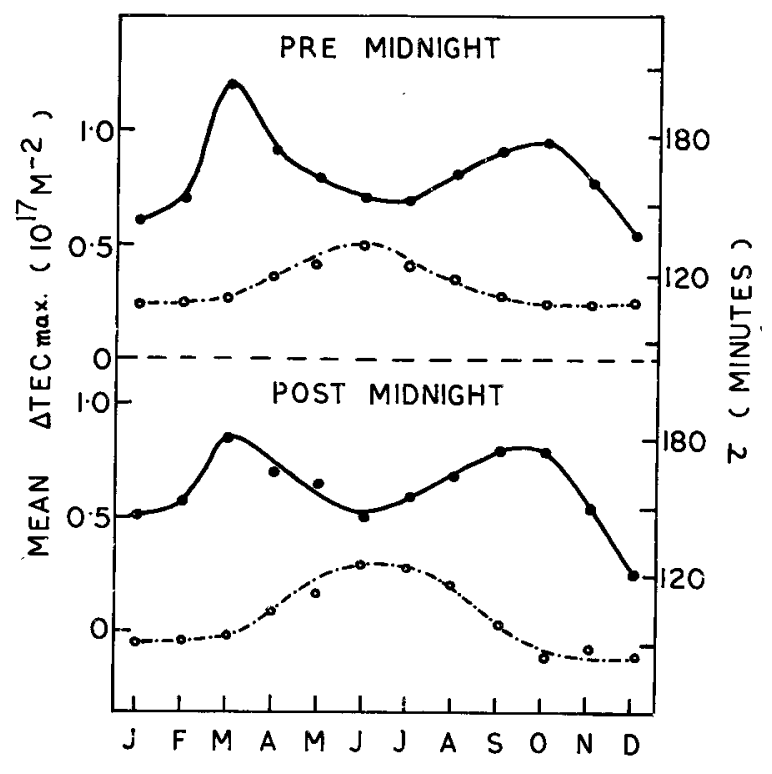

Figure 5. Monthly mean variation of $\tau(\circ \ldots-)$ and $\triangle T E C_{\max }(\bullet \ldots \rightarrow)$ of pre-midnight and post-midnight TEC enhancements at Hawaii.

maximum around summer months. The variation for the post-midnight enhancements is a bit more pronounced than that for pre-midnight. Seasonal variations of $\triangle \mathrm{TEC}_{\max }$ of pre-midnight and post-midnight enhancements, shown in the same figure (solid curves), reveal peak values during the equinoctial months.

The half-amplitude duration $\tau$ and the amplitude $\triangle \mathrm{TEC}_{\max }$ of TEC enhancements show very good correlation with solar activity. Mean values of $\tau$ and $\triangle \mathrm{TEC}_{\max }$ for both pre- and post-midnight enhancements vary essentially in the same manner as the sun spot number in all seasons as shown in figure 6 . In the case of $\triangle \mathrm{TEC}_{\max }$, however, the variation is sharper for pre-midnight than for post-midnight enhancements. Further, if one considers the enhancements in terms of the percentage of the daytime peak TEC, the variation would appear to be much less pronounced. While the daytime peak TEC and post-midnight $\triangle T E C_{\text {max }}$ vary by about the same factor over a solar cycle, the corresponding factor is about 1.5 times as great for the pre-midnight $\triangle \mathrm{TEC}_{\mathrm{max}}$.

\section{Discussion}

The results presented above provide a fairly comprehensive picture of the seasonal and solar cycle variations of anomalous night-time TEC enhancements at a low latitude. Seasonal variations of TEC enhancements presented here agree in general with those reported earlier (Yourig et al 1970; Janve et al 1979). However, there are some minor differences between the characteristics of TEC enhancements presented here for the American low latitude (Hawaii) and that reported by Janve et al (1979) for the Indian low latitudes. For example, seasonal variations of the duration $(\tau)$ shows maximum during summer at the American low latitude and minimum during the same season at the Indian low latitudes. The dependence of 


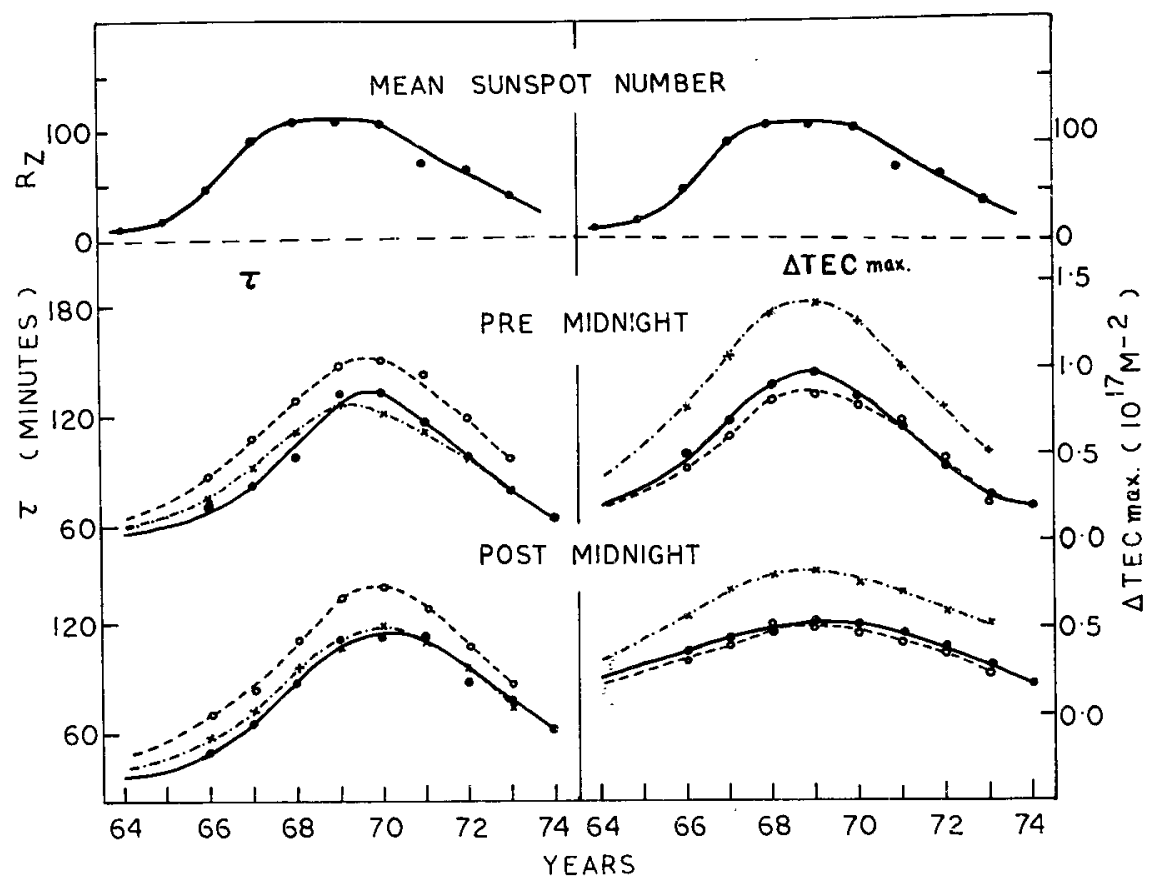

Figure 6. Solar cycle variation of yearly mean sunspot number and seasonal mean $\tau$ and $\triangle \mathrm{TEC}_{\max }$ of pre-midnight and post-midnight TEC enhancements for the three seasons $(\bullet-$ winter, $\circ--\circ$ summer and $\times \cdots \cdots+\cdots$ equinox) at Hawaii.

TEC enhancements on solar activity is studied here by considering TEC data for nearly a full solar cycle.

The potential source mechanisms for the observed night-time TEC enhancements at low latitudes are believed to be (a) plasma transfer from conjugate ionosphere and (b) electrodynamic drifts and neutral winds. There are a few other mechanisms linked with the phenomena of night-time TEC enhancements such as plasma diffusion from protonosphere (Titheridge, 1968a), Cross-L plasmaspheric compression and consequent enhancement in plasmasphere-ionosphere plasma flow (Davies et al, 1979) and corpuscular ionization (Titheridge 1968a) which are important only at mid and high latitudes.

According to conjugate point transfer mechanism of ionization (Rishbeth 1968; Wickwar 1974), the plasma transfer will occur only when there exists a large density or temperature gradient between two magnetically conjugate points. During winter, this large gradient is present because sun sets later at the conjugate summer hemisphere. The hypothesis of conjugate ionosphere as a source seems to be favoured by the following observational features as well: (a) the maximum frequency of occurrence of night-time electron content enhancements during winter, (b) the downward $\mathrm{H}^{+}$flux during winter nights and a corresponding upward flux during summer nights (Evans and Holt 1978), and (c) the positive correlation of TEC enhancement with solar activity in accordance with the solar cycle dependence of the electron density difference between the conjugate points. While the conjugate ionosphere seems relevant, it alone cannot account fully for 
the observed enhancements is clear from the enhancements which also occur during post-midnight hours when there is no solar EUV radiation at the conjugate ionosphere.

Neutral winds and electrodynamic drifts may also act as important source mechanism, especially to account for the post-midnight TEC enhancements. The pattern of the neutral winds are such that it has a strong N-S component directed towards the equator during 0100-0300 LT (Kohl and King 1967). The component shows a sharp gradient at low latitudes and this leads to a strong convergence of plasma with peak occurring at about the same latitude as the equatorial anomaly peak. The flux calculations show that the observed peak enhancement can be realized in about an hour. In addition to the neutral winds, electrodynamic drifts also can be of some significance for the low latitude enhancements. There is a strong eastward drift which drops rapidly with time after midnight in the latitude range of $0-30^{\circ} \mathrm{N}$ (Maeda and Kato 1966). This, when coupled to the $\mathrm{E}-\mathrm{W}$ gradients in the total electron content, can lead to a convergence of the plasma during post-midnight hours. Its contribution is about $1 / 3$ of that of the neutral winds. Thus, while no single process could account for the observed TEC enhancements, it does seem possible to meet the requirements, atleast qualitatively, on the basis of a combination of the processes as outlined above.

\section{References}

Davies K, Anderson D K, Paul A K, Degenhardt W, Hartmann G K and Leitinger R 1979 J. Geophys. Res. 841536

Essex D A and Klobuchar J A $1980 \%$. Geophys. Res. 856011

Evans J V 1965 J. Geophys. Res. 704331

Evans J V and Holt J M 1978 Planet. Space Sci. 36727

Janve A V, Rai R K, Deshpande M R, Rastogi R G, Jain A R, Malkiat Singh and Gurm H S 1979 Ann. Geophys. 35159

Klobuchar J A, Aarons J and Hajeb Hosseinich H $1968 \mathrm{~J}$. Geophys. Res. 737530

Kohl H and King J W 1967 J. Atmos. Terr. Phys. 291045

Leitinger R, Hartmann G K, Degenhardt W, Hedberg A and Tanskanen P 1982 J. Atmos. Terr. Phys. 44369

Maeda K and Kato S 1966 Space Sci. Rev. 557

Rishbeth H 1968 Rev. Geophys. 633

Roelofs T H 1973 Atlas of TEC plots (Honolulu: University of Hawaii) Vols 8-9

Titheridge J E 1968a J. Atmos. Terr. Phys. 301857

Titheridge J E 1968b J. Geophys. Res. 732985

Wickwar V B 1974 Planet. Space Sci. 221297

Young D M L, Yuen P C and Roelofs T H 1970 Planet. Space Sci. 181163

Yuen P C and Roelofs T H 1966 J. Geophys. Res. 71849

Yuen P C and Roelofs T H 1971 Atlas of TEC plots (Honolulu: University of Hawaii) Vols. 1-7 